\title{
OTRA Based Voltage Mode Third Order Quadrature Oscillator
}

\author{
Rajeshwari Pandey, ${ }^{1}$ Neeta Pandey, ${ }^{1}$ Gurumurthy Komanapalli, ${ }^{1}$ and Rashika Anurag ${ }^{2}$ \\ ${ }^{1}$ Department of Electronics and Communication Engineering, Delhi Technological University, Delhi 110042, India \\ ${ }^{2}$ Department of Electronics and Communication Engineering, JSS Academy of Technical Education, C-20/1 Sector 62, \\ NOI DA, Uttar Pradesh 201301, India
}

Correspondence should be addressed to Neeta Pandey; n66pandey@rediffmail.com

Received 2 February 2014; Accepted 9 March 2014; Published 29 April 2014

Academic Editors: S. Gift, R. Senani, and E. Tlelo-Cuautle

Copyright (C) 2014 Rajeshwari Pandey et al. This is an open access article distributed under the Creative Commons Attribution License, which permits unrestricted use, distribution, and reproduction in any medium, provided the original work is properly cited.

\begin{abstract}
Two topologies of operational transresistance (OTRA) based third order quadrature oscillators (QO) are proposed in this paper. The proposed oscillators are designed using a combination of lossy and lossless integrators. The proposed topologies can be made fully integrated by implementing the resistors using matched transistors operating in linear region, which also facilitates electronic tuning of oscillation frequency. The nonideality analysis of the circuit is also given and for high frequency applications self-compensation can be used. Workability of the proposed QOs is verified through PSPICE simulations using $0.5 \mu \mathrm{m}$ AGILENT CMOS process parameters. The total harmonic distortion (THD) for both the QO designs is found to be less than $1 \%$.
\end{abstract}

\section{Introduction}

Quadrature oscillators (QO) produce outputs having a phase difference of $90^{\circ}$. The phase-locked sine-cosine relationship of QO has useful applications in the field of telecommunications where the modulation scheme utilizes both inphase and quadrature components, such as single-sideband generators and quadrature mixers [1]. The QOs are also used extensively in the field of instrumentation and power electronics [2]. For these applications low value of total harmonic distortion (THD) is an essential requirement as higher harmonics have detrimental effects on electrical equipment. These higher order harmonics can also interfere with communication transmission lines since they oscillate at the same frequencies as the transmit frequency. If left unchecked, increased temperature and interference can greatly shorten the life of electronic equipment and cause damage to power systems.

It is well known that higher order networks as compared to lower order circuits provide better accuracy, frequency response, and distortion performance [3, 4]. However, it has been observed that higher order QO designs have not been explored much, as only a few third order QOs $[1,3-$ 16] have appeared in literature in recent years. A careful observation suggests that the reported QO designs are based on forming closed loop using (i) two lossy and one lossless integrators [3-5], (ii) one lossy and two lossless integrators [8], (iii) a second order low pass filter followed by an integrator $[1,6,7,10-16]$, and (iv) three low pass filters and gained feedback around the loop [9]. These topologies are designed using second generation current conveyor (CCII) [1, 6], second generation current-controlled conveyor (CCCII) [7-9], differential voltage current conveyor (DVCC) [10], op-amp [5], operational transconductance amplifier (OTA) [3], current difference transconductance amplifier (CDTA) $[4,11]$, operational transresistance amplifier (OTRA) [12], and current-controlled current difference transconductance amplifier (CCCDTA) [13]. The structure proposed in [15] uses differential difference current conveyor (DDCC) and OTA whereas design of [16] is based on CCCDTA and OTA.

The OTRA is a current input voltage output device [17]. Being a current processing block, it inherits all the advantages of current mode techniques [12] and provides voltage output at low impedance which can readily be used to drive voltage input circuits without increasing component count. An extensive literature review suggests though a large number of OTRA based second order QOs [17-21] are available in literature, yet only a single third order QO topology using 


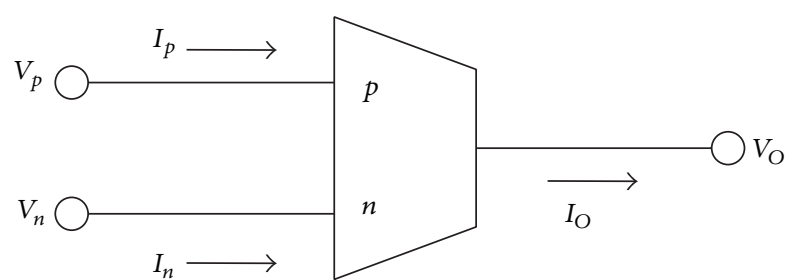

FIgURE 1: OTRA circuit symbol.

OTRA [12] is reported. This QO design is based on forming a closed loop using a second order low pass filter followed by an integrator.

In this paper two topologies of third order QO based on OTRA have been presented which use the scheme of lossy and lossless integrators. One of the proposed circuits makes use of one inverting lossy and two lossless integrators connected in a feedback forming closed loop whereas the other configuration uses one lossless and two lossy integrators to form closed loop. The proposed structures can be made fully integrated by implementing the resistors using matched transistors operating in linear region and can be tuned electronically.

\section{Circuit Description}

The OTRA is a high gain, current input voltage output analog building block [17]. The input terminals of OTRA are internally grounded, thereby eliminating response limitations due to parasitic capacitances and resistances and hence is a suitable choice for high frequency applications. The circuit symbol of OTRA is shown in Figure 1 and the port characteristics are given by (1), where $R_{m}$ is transresistance gain of OTRA:

$$
\left[\begin{array}{c}
V_{p} \\
V_{n} \\
V_{O}
\end{array}\right]=\left[\begin{array}{ccc}
0 & 0 & 0 \\
0 & 0 & 0 \\
R_{m} & -R_{m} & 0
\end{array}\right]\left[\begin{array}{c}
I_{p} \\
I_{n} \\
I_{O}
\end{array}\right] .
$$

For ideal operations the $R_{m}$ of OTRA approaches infinity and forces the input currents to be equal. Thus OTRA must be used in a negative feedback configuration [22].

2.1. Circuit I. The first QO topology is shown in Figure 2. It uses two lossless integrators and a lossy inverting integrator in the feedback forming a closed loop resulting in loop gain of the system as $A(s) \beta(s)$, where $A(s)$ is forward path gain involving OTRA 2 and OTRA 3 and $\beta(s)$ is feedback gain involving OTRA1.

The criterion for oscillations [23] to occur is given by

$$
1-A(s) \beta(s)=0 .
$$

If this criterion is satisfied, the closed loop system will result in two quadrature phase oscillations, available at nodes 1 and 2. Routine analysis of the circuit of Figure 2 results in the following characteristic equation:

$$
s^{3} c_{1} c_{2} c_{3} R_{2} R_{3}+\frac{s^{2} C_{2} C_{3} R_{2} R_{3}}{R_{4}}+s c_{3} \frac{R_{3}}{R_{5}}+\frac{1}{R_{1}}=0 .
$$

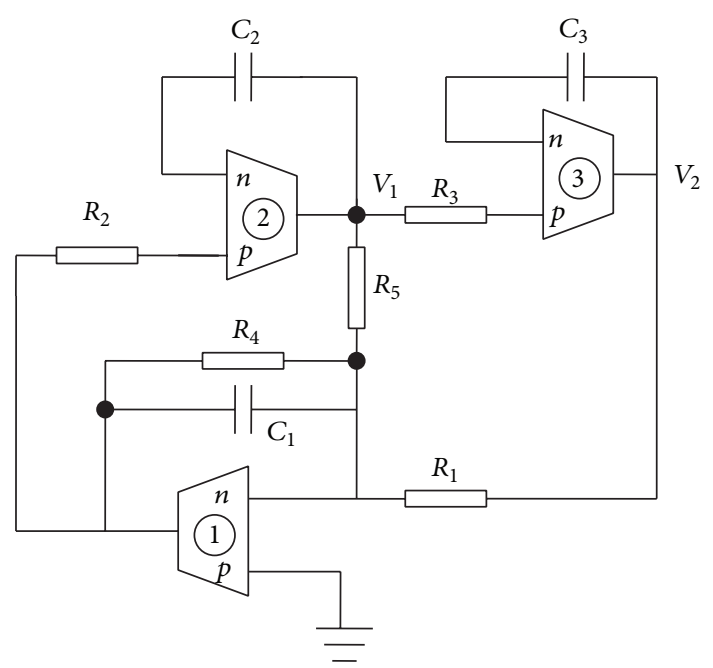

Figure 2: Proposed Circuit I.

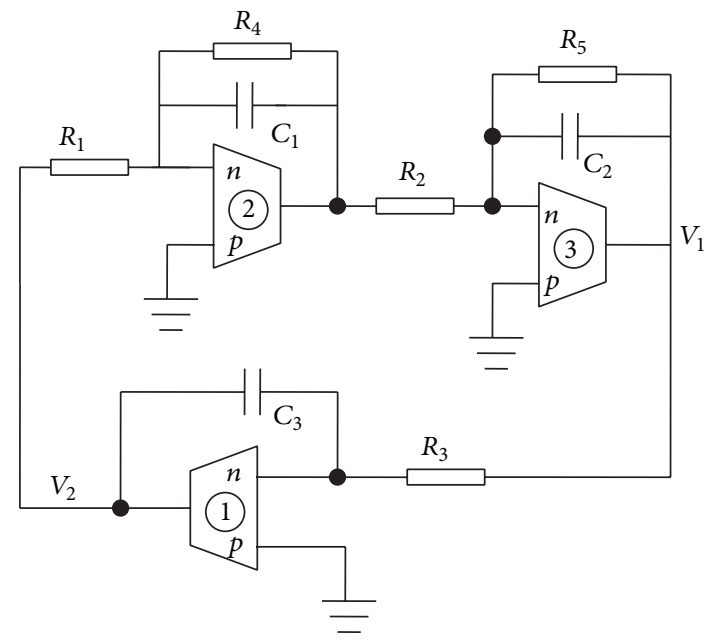

Figure 3: Proposed Circuit II.

From this characteristic equation the condition of oscillation (CO) and frequency of oscillation (FO) can be found to be FO:

$$
f=\frac{1}{2 \pi} \sqrt{\frac{1}{C_{1} C_{2} R_{2} R_{5}}}
$$

CO:

$$
R_{4} R_{5}=R_{1} R_{3}
$$

The FO can be adjusted to desired value through $R_{2}$ and proper selection of resistors $R_{1}, R_{3}$, and $R_{4}$ would satisfy the CO.

2.2. Circuit II. The second proposed QO configuration is shown in Figure 3 which makes use of two lossy and one lossless integrators, all in inverting mode. 


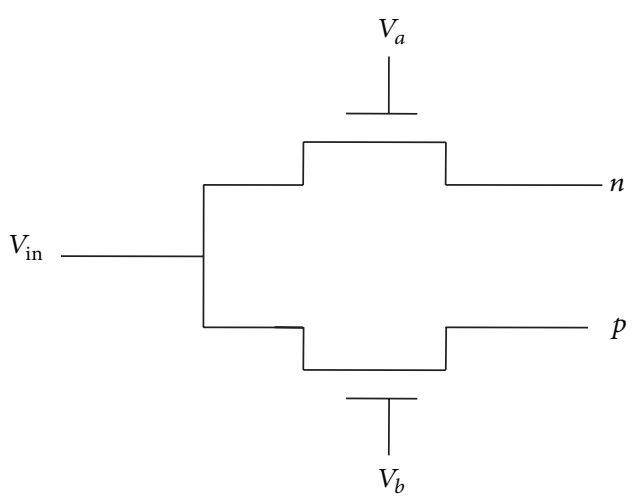

FIgURE 4: The MOS based resistor [17].

The characteristic equation of the Circuit II can be deduced as

$$
\begin{aligned}
s^{3} C_{1} C_{2} C_{3} R_{3} & +s^{2}\left(\frac{C_{2} C_{3} R_{3}}{R_{4}}+\frac{C_{1} C_{3} R_{3}}{R_{5}}\right)+\frac{s C_{3} R_{3}}{R_{4} R_{5}} \\
+ & \frac{1}{R_{1} R_{2}}=0
\end{aligned}
$$

FO:

$$
f=\frac{1}{2 \pi} \sqrt{\frac{1}{C_{1} C_{2} R_{4} R_{5}}},
$$

CO:

$$
R_{1} R_{2} R_{3} C_{3}\left[R_{4} C_{1}+R_{5} C_{2}\right]=R_{4}^{2} R_{5}^{2} C_{1} C_{2} .
$$

By suitable selection of $R_{4}$ and $R_{5}$ the FO can be adjusted to desired value and proper selection of resistors $R_{1}, R_{2}$, and $R_{3}$ results in desired CO.

The current differencing property of the OTRA makes it possible to implement the resistors connected to the input terminals of OTRA, using MOS transistors with complete nonlinearity cancellation [17]. Each resistor requires two matched n-MOSFETs connected in a manner as shown in Figure 4 which represents a typical MOS implementation of resistance connected at negative input of OTRA.

Symbols " $p$ " and " $n$ " represent the noninverting and the inverting terminals of the OTRA. As can be seen from the figure, the voltages at the drain and the source terminals for both MOSFETs are equal. On taking the difference of the currents flowing in the two transistors, the nonlinearity gets cancelled out. The resistor value realized can be expressed as

$$
R=\frac{1}{K_{N}\left(V_{a}-V_{b}\right)},
$$

where

$$
K_{N}=\mu C_{O X} \frac{W}{L}
$$

$K_{N}$ needs to be determined for the transistors being used to implement the resistors and $\mu, C_{O X}$, and $W / L$ represent standard transistor parameters. The MOS based implementations of Circuit I and Circuit II are shown in Figures 5 and 6 , respectively.

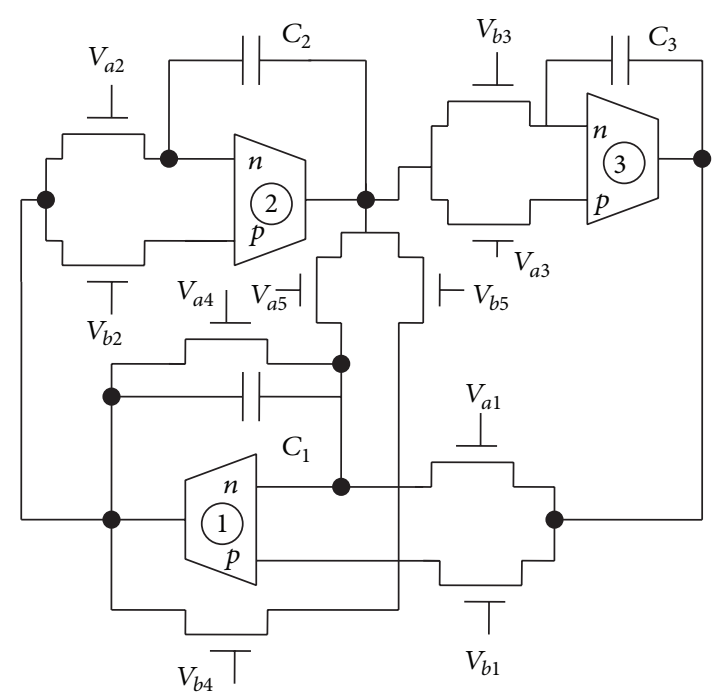

FIgURE 5: The MOS based implementation of QO Circuit I.

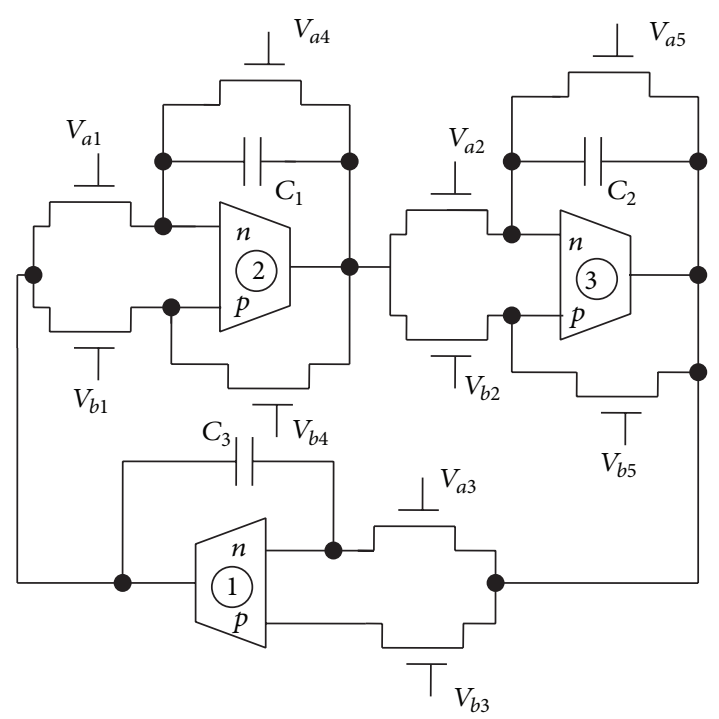

FIGURE 6: The MOS based implementation of QO Circuit II.

\section{Nonideal Analysis}

The output of the QO may deviate due to nonideality of OTRA in practice. Ideally the transresistance gain $R_{m}$ is assumed to approach infinity. However, practically $R_{m}$ is a frequency dependent finite value. Considering a single pole model for the transresistance gain, $R_{m}$ can be expressed as

$$
R_{m}(s)=\left(\frac{R_{0}}{1+\left(s / \omega_{0}\right)}\right) \text {, }
$$

where $R_{0}$ is $\mathrm{dc}$ transresistance gain. For high frequency applications the transresistance gain $R_{m}(s)$ reduces to

$$
R_{m}(s)=\left(\frac{1}{s C_{p}}\right) \text {, }
$$




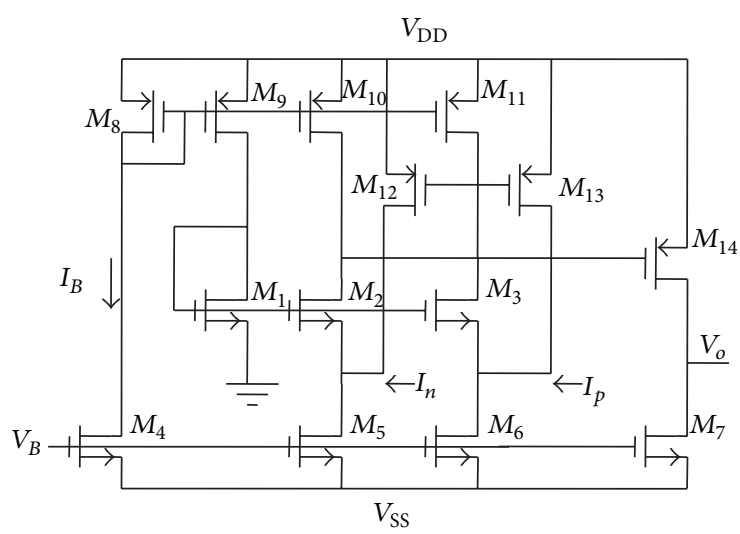

FiguRE 7: CMOS OTRA [22].

where

$$
C_{p}=\frac{1}{R_{0} \omega_{0}}
$$

Taking this effect into account (3) modifies to

$$
\begin{aligned}
s^{3}\left(c_{1}\right. & \left.+c_{p}\right)\left(c_{2}+c_{p}\right)\left(c_{3}+c_{p}\right) R_{2} R_{3} \\
& +s^{2}\left(c_{2}+c_{p}\right)\left(c_{3}+c_{p}\right) \frac{R_{2} R_{3}}{R_{4}} \\
& +s\left(c_{3}+c_{p}\right) \frac{R_{3}}{R_{5}}+\frac{1}{R_{1}}=0 .
\end{aligned}
$$

From (14) it is found that FO for Circuit I changes to

$$
f=\frac{1}{2 \pi} \sqrt{\frac{1}{\left(C_{1}+C_{p}\right)\left(C_{2}+C_{p}\right) R_{2} R_{5}}} .
$$

Due to nonideality effect of OTRA (6) changes to

$$
\begin{aligned}
& s^{3}\left(c_{1}+c_{p}\right)\left(c_{2}+c_{p}\right)\left(c_{3}+c_{p}\right) R_{3} \\
& +s^{2}\left(\left(c_{2}+c_{p}\right)\left(c_{3}+c_{p}\right) \frac{R_{3}}{R_{4}}+\left(c_{1}+c_{p}\right)\left(c_{3}+c_{p}\right) \frac{R_{3}}{R_{5}}\right) \\
& \quad+s\left(c_{3}+c_{p}\right) \frac{R_{3}}{R_{4} R_{5}}+\frac{1}{R_{1} R_{2}}=0 .
\end{aligned}
$$

The characteristic equation represented by (16) results in modified FO for Circuit II and is expressed as

$$
f=\frac{1}{2 \pi} \sqrt{\frac{1}{\left(C_{1}+C_{p}\right)\left(C_{2}+C_{p}\right) R_{4} R_{5}}} .
$$

The effect of $C_{p}$ can be eliminated by preadjusting the values of capacitors $C_{1}, C_{2}$, and $C_{3}$, thus achieving selfcompensation.

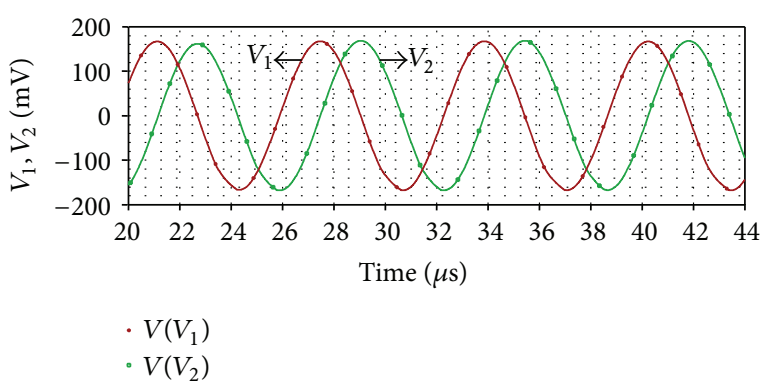

FIGURE 8: Transient output of proposed QO Circuit I.

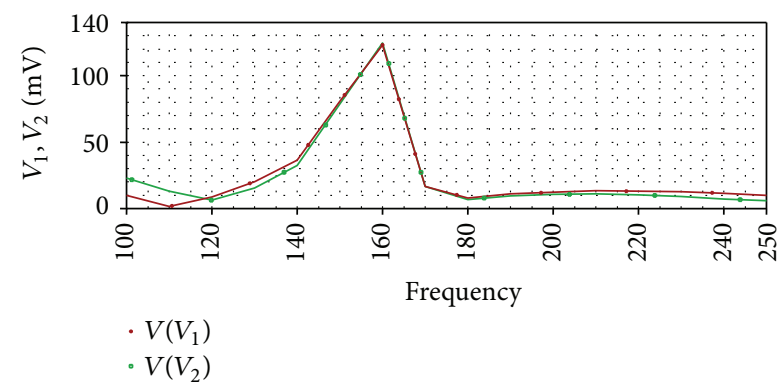

FIGURE 9: Frequency spectrum of output of QO Circuit I.

\section{Simulation Results}

The proposed QO is verified through simulations using the CMOS implementation of the OTRA [22] which is shown in Figure 7. The SPICE simulations are performed using $0.5 \mu \mathrm{m}$ CMOS process parameters provided by MOSIS (AGILENT). Supply voltages taken are $\pm 1.5 \mathrm{~V}$. Both the QO topologies are designed for an $\mathrm{FO}$ of $159 \mathrm{KHz}$ and the simulated value was observed to be $161 \mathrm{KHz}$ for Circuits I and II, respectively. The simulated transient output and corresponding frequency spectrum for Circuit I are shown in Figures 8 and 9, respectively, and those for Circuit II are depicted in Figures 10 and 11. The percentage total harmonic distortion (THD) is $0.57 \%$ for QO Circuit I and that for Circuit II is observed to be $0.7 \%$. These values are considerably low as compared to $6.3 \%$ THD of QO circuit of [12].

\section{Conclusion}

Two topologies of third order OTRA based quadrature oscillator are presented in this paper using lossy and lossless integrators. The simulations are performed using PSPICE and it is observed that the results are in close agreement with theoretical propositioned. The simulated value of \% THD in both the circuits is quite low as compared to other third order structures available in literature. The effect of nonideal behavior of OTRA and high frequency compensation scheme has also been included in the proposed theory. 


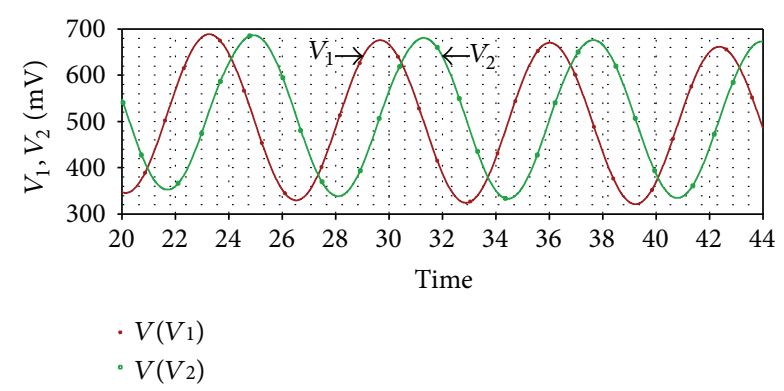

FIgURE 10: Transient output of proposed QO Circuit II.

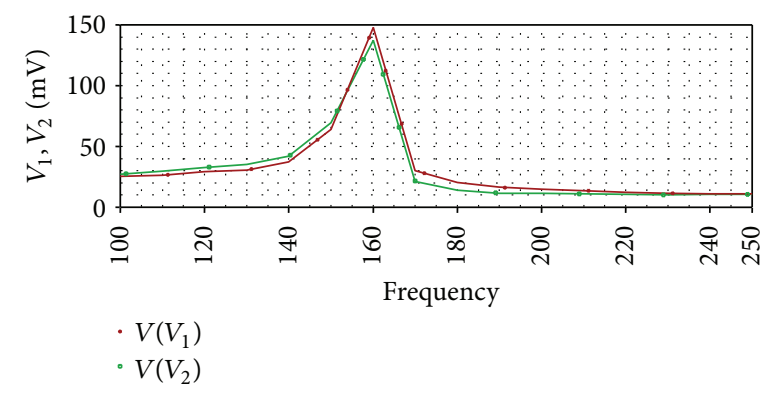

FIGURE 11: Frequency spectrum of output of QO Circuit II.

\section{Conflict of Interests}

The authors declare that there is no conflict of interests regarding the publication of this paper.

\section{References}

[1] J.-W. Horng, C.-L. Hou, C.-M. Chang, W.-Y. Chung, H.-W. Tang, and Y.-H. Wen, "Quadrature oscillators using CCIIs," International Journal of Electronics, vol. 92, no. 1, pp. 21-31, 2005.

[2] J.-W. Horng, C.-L. Hou, C.-M. Chang, H.-P. Chou, C.-T. Lin, and Y.-H. Wen, "Quadrature oscillators with grounded capacitors and resistors using FDCCIIs," ETRI Journal, vol. 28, no. 4, pp. 486-493, 2006.

[3] P. Prommee and K. Dejhan, "An integrable electroniccontrolled quadrature sinusoidal oscillator using CMOS operational transconductance amplifier," International Journal of Electronics, vol. 89, no. 5, pp. 365-379, 2002.

[4] J.-W. Horng, "Current-mode third-order quadrature oscillator using CDTAs," Active and Passive Electronic Components, vol. 2009, Article ID 789171, 5 pages, 2009.

[5] J.-W. Horng, "Quadrature oscillators using operational amplifiers," Active and Passive Electronic Components, vol. 2011, Article ID 320367, 2011.

[6] J.-W. Horng, "Current/voltage-mode third order quadrature oscillator employing two multiple outputs CCIIs and grounded capacitors," Indian Journal of Pure and Applied Physics, vol. 49, no. 7, pp. 494-498, 2011.

[7] S. Maheshwari and I. A. Khan, "Current controlled third order quadrature oscillator," IEE Proceedings-Circuits Devices and Systems, vol. 152, pp. 605-607, 2005.

[8] S. Maheshwari and I. A. Khan, "Current-mode third-order quadrature oscillator," IET Circuits, Devices and Systems, vol. 4, no. 3, pp. 188-195, 2010.
[9] S. Maheshwari and R. Verma, "Electronically tunable sinusoidal oscillator circuit," Active and Passive Electronic Components, vol. 2012, Article ID 719376, 6 pages, 2012.

[10] S. Maheshwari, "Analogue signal processing applications using a new circuit topology," IET Circuits, Devices and Systems, vol. 3, no. 3, pp. 106-115, 2009.

[11] J.-W. Horng, H. Lee, and J.-Y. Wu, "Electronically tunable thirdorder quadrature oscillator using CDTAs," Radioengineering, vol. 19, no. 2, pp. 326-330, 2010.

[12] R. Pandey, N. Pandey, and S. K. Paul, "MOS-C third order quadrature oscillator using OTRA," in Proceedings of the $3 \mathrm{rd}$ International Conference on Computer and Communication Technology, pp. 77-80, November 2012.

[13] S. Lawanwisut and M. Siripruchyanun, "High outputimpedance current-mode third-order quadrature oscillator based on CCCCTAs," in Proceedings of the IEEE Region 10 Conference (TENCON '09), pp. 1-4, November 2009.

[14] A. Kwawsibsam, B. Sreewirote, and W. Jaikla, "Third-order voltage-mode quadratrue oscillator using DDCC and OTAs," in International Conference on Circuits, System and Simulation, pp. 317-321, 2011.

[15] M. Kumngern and S. Junnapiya, "Current-mode third-order quadrature oscillator using minimum elements," in Proceedings of the International Conference on Electrical Engineering and Informatics (ICEEI '11), pp. 1-4, July 2011.

[16] D. Duangmalai and W. Jaikla, "Realization of current-mode quadrature oscillator based on third order technique," ACEEE International Journal on Electrical and Power Engineering, vol. 2, pp. 46-49, 2011.

[17] K. N. Salama and A. M. Soliman, "CMOS operational transresistance amplifier for analog signal processing," Microelectronics Journal, vol. 30, no. 3, pp. 235-245, 1999.

[18] K. N. Salama and A. M. Soliman, "Universal filters using Operational Transresistance Amplifiers," AEU-Archiv für Elektronik und Ubertragungstechnik, vol. 53, no. 1, pp. 49-52, 1999.

[19] S. Kilinç and U. Çam, "Operational transresistance amplifier based first-order allpass filter with an application example," in Proceedings of the 47th Midwest Symposium on Circuits and Systems, vol. 1, pp. 65-68, July 2004.

[20] S. Kilinç and U. Çam, "Cascadable allpass and notch filters employing single operational transresistance amplifier," Computers and Electrical Engineering, vol. 31, no. 6, pp. 391-401, 2005.

[21] C. Cakir, U. Cam, and O. Cicekoglu, "Novel allpass filter configuration employing single OTRA," IEEE Transactions on Circuits and Systems II: Express Briefs, vol. 52, no. 3, pp. 122-125, 2005.

[22] H. Mostafa and A. M. Soliman, "A modified CMOS realization of the operational transresistance amplifier (OTRA)," Frequenz, vol. 60, no. 3-4, pp. 70-76, 2006.

[23] A. S. Sedra and K. C. Smith, Microelectronic Circuits., Oxford University Press, New York, NY, USA, 2004. 

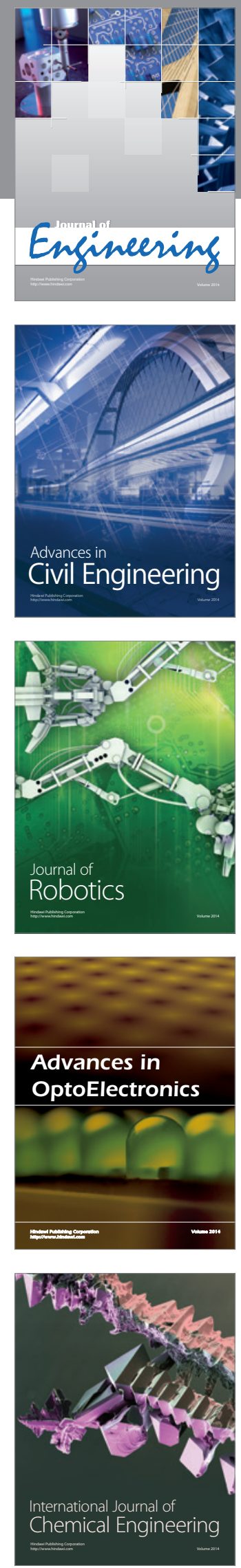

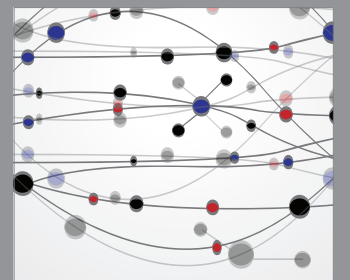

The Scientific World Journal
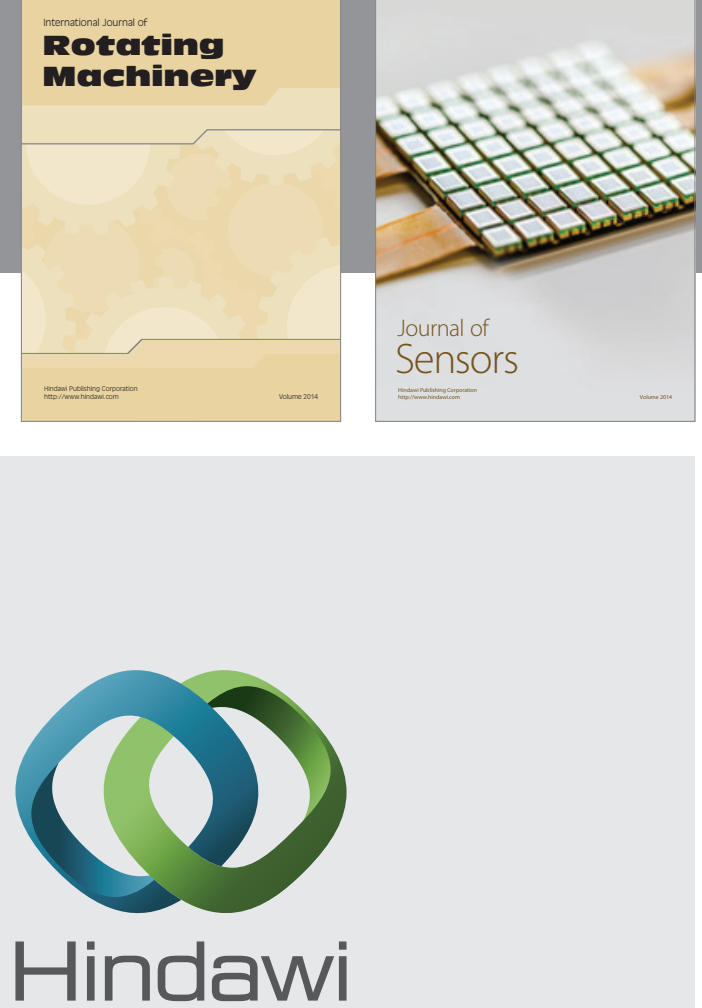

Submit your manuscripts at http://www.hindawi.com
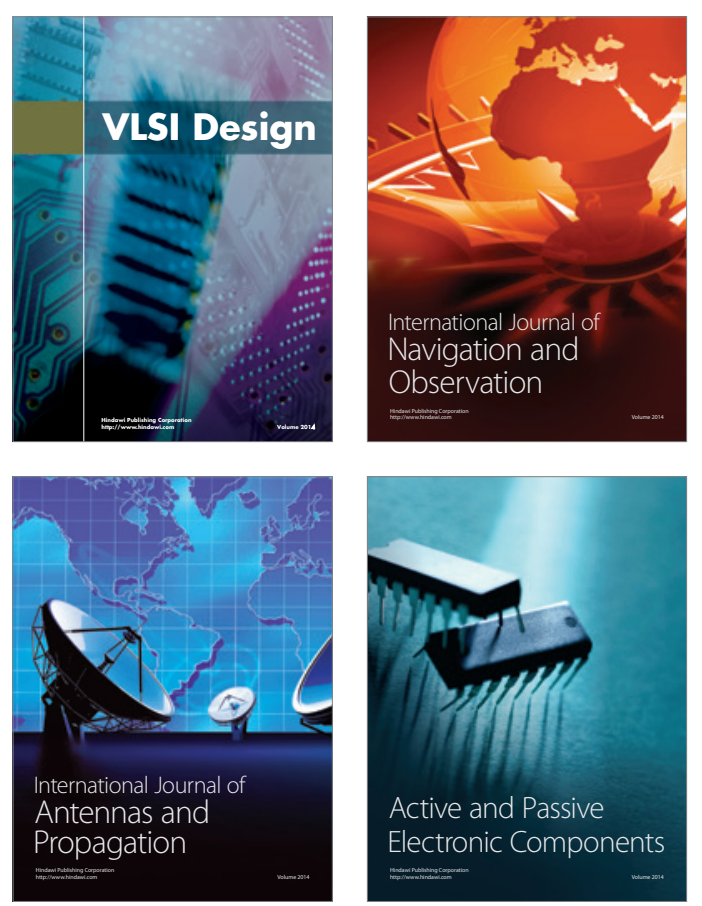
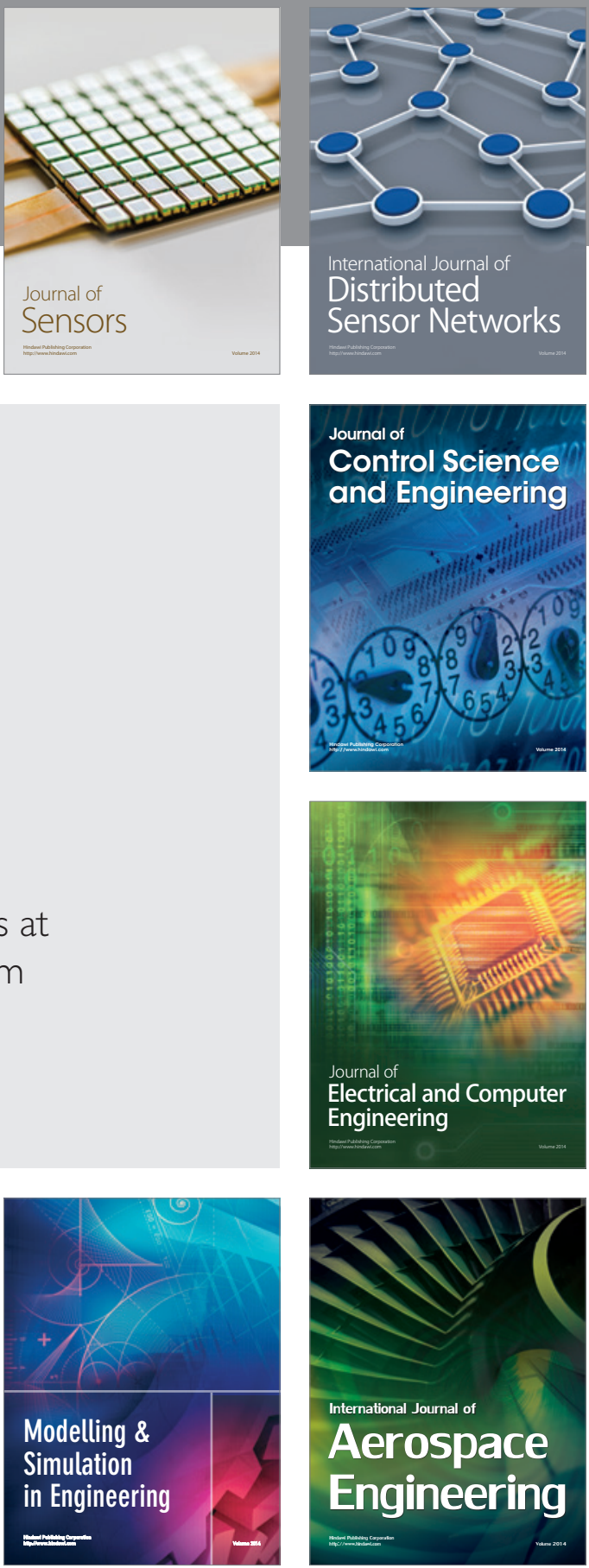

Journal of

Control Science

and Engineering
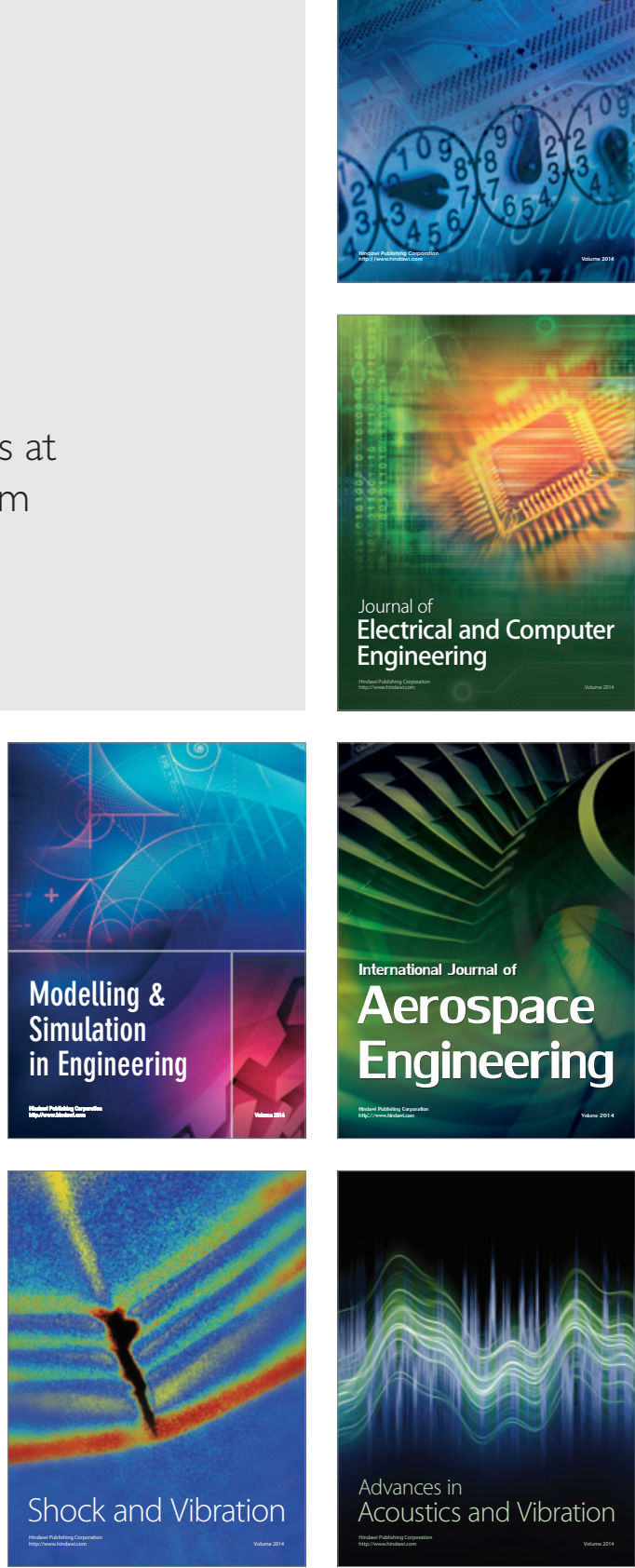